\title{
The Chloroplast Reactive Oxygen Species-Redox System in Plant Immunity and Disease
}

\author{
Elżbieta Kuźniak* and Tomasz Kopczewski \\ Department of Plant Physiology and Biochemistry, Faculty of Biology and Environmental Protection, University of Lodz, Lodz, \\ Poland
}

Pathogen infections limit plant growth and productivity, thus contributing to crop losses. As the site of photosynthesis, the chloroplast is vital for plant productivity. This organelle, communicating with other cellular compartments challenged by infection

OPEN ACCESS

Edited by:

José Manuel Palma,

Consejo Superior de Investigaciones

Científicas (CSIC), Spain

Reviewed by:

Néstor Carrillo,

Consejo Nacional de Investigaciones Cientificas y Técnicas (CONICET),

Argentina

Agepati S. Raghavendra,

University of Hyderabad, India

*Correspondence:

Elżbieta Kuźniak

elzbieta.kuzniak@biol.uni.lodz.pl

Specialty section:

This article was submitted to

Plant Metabolism

and Chemodiversity,

a section of the journal

Frontiers in Plant Science

Received: 15 June 2020

Accepted: 27 October 2020

Published: 12 November 2020

Citation:

Kuźniak E and Kopczewski T (2020) The Chloroplast Reactive Oxygen Species-Redox System in Plant Immunity and Disease.

Front. Plant Sci. 11:572686.

doi: 10.3389/fp/s.2020.572686 (e.g., apoplast, mitochondria, and peroxisomes), is also a key battlefield in the plantpathogen interaction. Here, we focus on the relation between reactive oxygen species (ROS)-redox signaling, photosynthesis which is governed by redox control, and biotic stress response. We also discuss the pathogen strategies to weaken the chloroplastmediated defense responses and to promote pathogenesis. As in the next decades crop yield increase may depend on the improvement of photosynthetic efficiency, a comprehensive understanding of the integration between photosynthesis and plant immunity is required to meet the future food demand.

Keywords: chloroplasts, defense response, pathogens, redox signaling, stress hormones

\section{THE IMPLICATION OF CHLOROPLASTS IN PLANT DEFENSE}

Plant diseases significantly reduce the yield of agricultural production worldwide (Nelson, 2020). In plants, there is an antagonistic relationship between immunity and growth, known as the growthimmunity trade-off. Immune responses temporarily suppress plant growth and vice versa-intense growth can hinder the defense reactions. A likely mechanism of this trade-off is the diversion of photosynthesis-derived energy and metabolites to the defense-related pathways instead of growth. The recognition of pathogen results in downregulation of growth mediated by phytohormones and upregulation of defense-related genes (Karasov et al., 2017). In Arabidopsis, constitutive accumulation of salicylic acid (SA) correlates with increased resistance to Peronospora parasitica but negatively affects growth (Mauch et al., 2001). Other studies also indicate that SA, a plant defense hormone, contributes to the homeostasis of plant growth and immunity (Ding and Ding, 2020).

Chloroplasts are not only vital for plant productivity, but they are also active sensors of the environment integrating the cellular response to stress. They significantly participate in the generation of ROS and NO, play a central role in redox homeostasis and retrograde signaling regulating nuclear gene expression (Foyer, 2018; Dietz et al., 2019). Their role in immunity is supported by observations that plant resistance to pathogens differ between light and dark, 
and light and functional chloroplasts are needed for defense responses (Roden and Ingle, 2009; Kuźniak et al., 2010).

Chloroplasts are also involved in stress hormone signaling by providing biosynthetic precursors for SA, jasmonic acid (JA), abscisic acid (ABA), and ethylene (ET) (Baier and Dietz, 2005; $\mathrm{Lu}$ and Yao, 2018).

As a signaling hub for regulating plant stress responses, chloroplasts are also targets for pathogen effectors and phytotoxins to suppress host defense, which makes them a key battlefield in plant-pathogen interactions (Park et al., 2018).

Here, we discuss the contribution of chloroplasts to plant immunity and their role as a target to pathogen manipulation weakening plant defense. Considering the internal redox environment of the chloroplast and the role of redox regulations in mediating plant responses to stress, we focus on the processes that directly or indirectly depend on chloroplast-associated ROS and redox changes. The role of ROS and redox components in retrograde signaling is not emphasized as it has recently been extensively reviewed (Dietz et al., 2019).

\section{THE PTI/ETI MODEL OF PLANT IMMUNITY}

The plant immune system relies on patterns-triggered immunity (PTI) and effector-triggered immunity (ETI) which are defined by the recognition mechanism of invading pathogens. PTI, responsible for the non-host-specific resistance, is activated following recognition of pathogen-associated molecular patterns (PAMP) by receptors at the cell surface. PTI initiates defense responses associated with ROS generation, stomata closure, activation of mitogen-activated protein kinases (MAPK) and induction of defense genes. Recognition of the avirulence (Avr) genes-coded pathogen effector proteins by cytoplasmic resistance (R) protein receptors triggers ETI which is more robust than PTI and includes the local hypersensitive response (HR) often followed by systemic acquired resistance in the host (Cook et al., 2015). HR is a specialized form of programmed cell death (PCD) characterized by a rapid cell death at the point of pathogen penetration that usually leads to or is linked to resistance associated with Nucleotide Binding Site and Leucine-Rich Repeat domains (NBS-LRR) R-proteins, but is not restricted to the ETI. HR is competent against biotrophs which grow and reproduce in living hosts but it may be beneficial for necrotrophs feeding on dead tissues (Balint-Kurti, 2019).

Oxidative burst associated with a biphasic accumulation of ROS, mainly $\mathrm{O}_{2}{ }^{-}$and $\mathrm{H}_{2} \mathrm{O}_{2}$, is a hallmark of plant interactions with incompatible pathogens. The first, nonspecific phase of ROS generation is linked to the activity of NADPH oxidase respiratory burst homolog $(\mathrm{RBOH})$ and class III cell wall peroxidases in the apoplast whereas the second one is specifically associated with ETI and occurs in chloroplasts (Shapiguzov et al., 2012). Apoplastic ROS accumulation is sensed in all cellular compartments via different redox-based mechanisms, and ROS produced in the apoplast and in chloroplasts, mitochondria, and peroxisomes are involved in interorganellar communication to trigger the immune response (Mignolet-Spruyt et al., 2016). The oxidative burst originating in different compartments trigger redox-modulated SA signaling with NPR1 (non-expressor of pathogenesis-related gene 1) being the master redox sensor for SA-mediated gene expression in the defense response (Seyfferth and Tsuda, 2014; Herrera-Vásquez et al., 2015).

\section{STRUCTURAL PATHWAYS UNDERLYING CHLOROPLAST SIGNALING}

The decrease in the number and size of chloroplasts, the occurrence of plastoglobules and degradation of thylakoids were found markers of biotic stress (Gabara et al., 2012; Zechmann, 2019). In Botrytis cinerea-infected plants these changes have been attributed to the accumulation of ROS, especially $\mathrm{H}_{2} \mathrm{O}_{2}$ in chloroplasts (Rossi et al., 2017). Chloroplasts communicate with other organelles via signaling networks and by establishing physical contact with them (Park et al., 2018). Activation of PTI, ETI, and PCD-promoting signals such as $\mathrm{H}_{2} \mathrm{O}_{2}$ and $\mathrm{SA}$, trigger chloroplast re-localization, clustering around the nucleus, and extending stromules, the stroma-filled tubules (Caplan et al., 2015; Ding et al., 2019). A decline in photosynthesis, often accompanying plant immunity, and increase in ROS generation within chloroplasts are likely pre-requisites for stromule formation (Brunkard et al., 2015; de Torres Zabala et al., 2015). During HR, chloroplasts are the major source of $\mathrm{H}_{2} \mathrm{O}_{2}$ which is a defense signaling molecule and induces nuclear gene expression (Yao and Greenberg, 2006). Stromules could facilitate the direct transfer of chloroplast-sourced $\mathrm{H}_{2} \mathrm{O}_{2}$ to the nucleus. Stromule formation increases with enhanced ROS generation in chloroplasts and its frequency is regulated in response to the chloroplast redox status (Brunkard et al., 2015; Caplan et al., 2015; Exposito-Rodriguez et al., 2017). Specific sub-sets of chloroplasts harboring the MSH1 (MUTS HOMOLOG1) protein function as sensory plastids and participate in epigenetic stress memory in plants (Foyer, 2018). MSH1 silencing results in differential expression of biotic stress-related genes and the function of MSH1 is associated with redox state of these chloroplasts (Virdi et al., 2015).

\section{THE CHLOROPLASTIC ELECTRON TRANSPORT CHAIN CARRIERS AND THEIR LINKS TO PLANT DEFENSE}

The chloroplast redox state is determined by electron flow through the photosynthetic electron transport chain (PETC) with plastoquinone $(\mathrm{PQ})$ proposed to be the central redox regulator (Potters et al., 2010; Liu and Lu, 2016). PQ is also involved in plant immune response. Light-induced redox changes of the PQ pool regulated HR and defense gene expression (Mühlenbock et al., 2008). PQ content increased in plants treated with pathogenderived elicitor and acting as an antioxidant, PQ mediated 
the ROS balance during oxidative stress induced by elicitation (Maciejewska et al., 2002). In Mesembryanthemum crystallinum, the $P Q$ redox state modified the response to $B$. cinerea by affecting the activity of antioxidant enzymes and the HR-like response was promoted when the PQ pool was reduced (Nosek et al., 2015). PQ is involved in ABA biosynthesis through the oxidative cleavage of epoxy-carotenoids (Rock and Zeevaart, 1991) and thus linked with the hormone-regulated defense. As PQ reduces $\mathrm{O}_{2}$ to $\mathrm{O}_{2} \cdot{ }^{-}$by semiquinone and $\mathrm{O}_{2}{ }^{-}$to $\mathrm{H}_{2} \mathrm{O}_{2}$ by hydroquinone, PQ also regulates defense signaling mediated by these two ROS (Camejo et al., 2016). In Arabidopsis, 50 nuclear genes is regulated by the redox state of PQ and the kinases STN7 and CSK1 are involved in this signaling. PQ may also regulate gene expression indirectly through the generation of $\mathrm{H}_{2} \mathrm{O}_{2}$ (Adamiec et al., 2008; Pfannschmidt et al., 2009).

Ferredoxin, the most upstream electron acceptor in PETC, determines the redox status of downstream reductants, e.g., $\mathrm{NADPH}$ and thioredoxins. NADPH produced in chloroplasts by ferredoxin-NADP ${ }^{+}$reductase is used in defense-related anabolic processes and in the regeneration of antioxidants by NADPH-dependent enzymes (Noctor et al., 2006). Ferredoxin and NADPH are involved in redox signaling via ferredoxinand NADPH-dependent thioredoxin reductases localized in chloroplasts as well as maintenance of redox balance mediated by ascorbate-glutathione cycle. Both processes are implicated in regulating disease resistance (Kuźniak and Skłodowska, 2005; Potters et al., 2010; Hanke and Mulo, 2013). In Arabidopsis, NADPH-dependent thioredoxin reductase C (NTRC) working together with $\mathrm{H}_{2} \mathrm{O}_{2}$-reducing 2-Cys peroxiredoxin play a role in innate immunity to non-host Pseudomonas syringae pathogens. This redox detoxification system regulates $\mathrm{H}_{2} \mathrm{O}_{2}$ generated in chloroplasts and functions as a negative regulator of diseaseassociated cell death. The increased susceptibility of Arabidopsis ntrc mutant to non-host $P$. syringae correlated with enhanced JA-dependent signaling (Ishiga et al., 2016).

The main leaf ferredoxin, $\mathrm{Fd} 2$ is required for resistance against pathogens. Fd2 plays a positive role in PTI-mediated ROS accumulation but negatively regulates the ETI response. The Fd2-knockout mutants exhibited increased susceptibility to virulent $P$. syringae pv. tomato DC3000 and the powdery mildew Golovinomyces cichoracearum. The Fd2-knockout mutant accumulated more JA following P. syringae pv. tomato DC3000 infection whereas the SA-mediated defense was compromised (Wang et al., 2018).

Imbalance in PETC may initiate and modulate defense responses, e.g., via ROS-mediated chloroplast-to-nucleus signaling (Karpiński et al., 2013). As activation of immune responses requires redox-mediated transcriptome reprogramming, the ferredoxin-dependent availability of NADPH and redox status of chloroplast thioredoxins may modify chloroplast retrograde signaling and affect nuclear gene expression (Rintamäki et al., 2009). In Arabidopsis, 286 nuclear genes were identified to be under the photosynthetic redox control and 76 of these genes encoded products with known functions, e.g., stress response (Fey et al., 2005). Moreover, Fd2 localizes in stromules and therefore it could reduce the redox-regulated transcription factors (TFs), including those required for the expression of SA-dependent genes (Fobert and Després, 2005; Wang et al., 2018).

\section{CAROTENOID, UNSATURATED FATTY ACIDS, AND TOCOPHEROL DERIVED SIGNALING}

In the chloroplast membranes, unsaturated fatty acids, carotenoids, and tocopherols act as ROS quenchers and their oxidation products can regulate defense responses. Tocopherols transfer the stress signals outside the chloroplast, possibly by influencing redox signaling in other organelles. Recently, tocopherols were shown to access endoplasmic reticulum (ER) via hemifused-membranes at plastid-ER contact sites (Mehrshahi et al., 2014). Under stress, changes in the content and composition of tocopherols modulate nuclear gene expression, the profiles of SA, JA, ABA, and ET as well as the formation of defense-related lipid peroxidation products. A link between redox and hormone signaling mediated, respectively, by $\gamma$-tocopherol and Ethylene Response Factors (ERFs) which integrates $\mathrm{ABA}, \mathrm{JA}$, and ET response to infection, found in vitamin E-deficient Arabidopsis mutant, likely represents a mechanism of chloroplast to nucleus retrograde signaling (Müller and Munné-Bosch, 2015; Allu et al., 2017). Altered tocopherol composition in chloroplasts negatively influenced Arabidopsis response to $B$. cinerea through enhanced lipid peroxidation and delayed defense activation (Cela et al., 2018).

Apocarotenoids are the products of oxidative cleavage of carotenoids. Interestingly, SA content increase in response to excess light which inhibits ROS accumulation in chloroplasts is dependent on apocarotenoid, $\beta$-cyclocitral which interferes with the SA signaling by regulating the localization of NPR1 in the nucleus (Hou et al., 2016).

Pathogens elicit the accumulation of oxylipins which are the products of peroxidation of polyunsaturated fatty acids (PUFA), and those with $\alpha, \beta$-unsaturated carbonyls are reactive electrophilic species (RES). The generation of oxylipins in chloroplasts can activate defense signaling and has an impact on gene expression (Farmer and Mueller, 2013). JA originated form PUFA controls gene expression through CORONATINEINSENSITIVE 1 (COI1), JASMONATE-ZIM DOMAIN (JAZ) proteins, and MYC TFs (Pieterse et al., 2009). RES signal transduction involves the class II TGA TFs and is enhanced by SA, known to inhibit JA signaling. Thus, JA and RES play distinct roles in mediating plant-defense responses (Findling et al., 2018). Moreover, oxylipins identified as signaling molecules, contribute to defense as antimicrobial agents inhibiting pathogen spore germination and growth (Prost et al., 2005).

The production of ${ }^{1} \mathrm{O}_{2}$, the predominant ROS in chloroplasts, can increase during pathogenesis favoring oxidative burst. PUFA in thylakoid membranes may act as structural ${ }^{1} \mathrm{O}_{2}$ scavengers (Farmer and Mueller, 2013). The protective role of PUFA during pathogenesis was shown in Arabidopsis where genetic removal of triunsaturated fatty acids led to increased susceptibility to B. cinerea (Mène-Saffrané et al., 2009). Moreover, in Arabidopsis$P$. syringae interaction, massive lipid oxidation is confined to 
plastid lipids and the HR-related PCD is preceded by ${ }^{1} \mathrm{O}_{2}$ dependent lipid peroxidation (Zoeller et al., 2012).

There is compelling evidence that tetrapyrrole signaling contributes to abiotic stress tolerance (Larkin, 2016) but to the best of our knowledge there are no data directly indicating its role in plant-pathogen interactions.

\section{CHLOROPLAST-GENERATED ROS IN PLANT-PATHOGEN INTERACTIONS}

Chloroplasts can perceive and propagate PTI signals generated in the apoplast following pathogen recognition. Application of flg22, a conserved peptide of bacterial flagellin, to Arabidopsis leaves induces CAS (Calcium-Sensing Sensor)-mediated calcium signaling in the chloroplast stroma. CAS mediated both the basal defense responses (PTI) and HR (ETI) leading to downregulation of photosynthesis-related genes and upregulation of the defensive genes (Nomura et al., 2012). ROS production in chloroplasts was linked to PAMP-induced downregulation of non-photochemical quenching (NPQ) due to weaker accumulation of PSII protein subunits. These PAMP-induced changes in redox balance prime chloroplasts to respond with massive ROS burst upon recognition of effectors during ETI (Göhre et al., 2012). Increased ETIrelated ROS contribute to HR-like cell death mediated by MAPK and light-dependent ROS generation in chloroplasts is preceded by inhibition of photosynthetic $\mathrm{CO}_{2}$ fixation (Liu et al., 2007; Zurbriggen et al., 2009). Moreover, Arabidopsis plants in which $\mathrm{H}_{2} \mathrm{O}_{2}$ generation at PSI was abolished were more susceptible to $P$. syringae pv tomato mutant which lacks the ability to secrete effectors, and so only elicits PTI. In this system the pathogenicity of the mutant was rescued (Göhre et al., 2012).

The level of ferredoxin decreases under stress and functional replacement of ferredoxin by a cyanobacterial flavodoxin confer resistance to biotic stress in tobacco. These plants infected with $B$. cinerea showed sustained photosynthetic electron flow, decreased ROS accumulation and enhanced resistance to this necrotroph which invasion is known to be facilitated by HR and oxidative processes mediated by ROS (Govrin and Levine, 2000; Rossi et al., 2017).

ROS-related signaling and the expression of defense require fine-tuning of the prooxidant-antioxidant balance in chloroplasts (Das and Roychoudhury, 2014). Pathogens could activate abiotic stress tolerance mechanisms related to ROS managements to promote virulence and plants defective in these systems and overproducing ROS show increased resistance to pathogens (Sowden et al., 2018). However, the effects depend on ROS amount, timing, and the plant-pathogen interaction. For example, during a non-host interaction of tobacco-Xanthomonas campestris pv vesicatoria, ROS generated in chloroplasts were essential for the development of HR but not for the induction of pathogenesis-related (PR) genes, and JA and SA accumulation (Zurbriggen et al., 2009). Moreover, the ROS homeostasis is coordinated by $\mathrm{NO}$ and the interplay of $\mathrm{H}_{2} \mathrm{O}_{2}$ and $\mathrm{NO}$ affects the immune response. The interaction of these redox molecules is required for $\mathrm{HR}, \mathrm{NO}$ inhibits NADPH oxidase and PCD, and NO-mediated modifications of ascorbate peroxidase and other antioxidant enzymes have regulatory functions under biotic stress (Frederickson Matika and Loake, 2014; Saxena et al., 2016). Moreover, nitrosoglutathione (GSNO), a NO-derived molecule, facilitates the oligomerization of NPR1 through thiol S-nitrosylation (Lindermayr et al., 2010; Corpas et al., 2013).

Infected plants experience episodes of reduced $\mathrm{CO}_{2}$ availability to photosynthesis because both foliar pathogenesis and resistance responses can result in stomata closure (Melotto et al., 2008; Grimmer et al., 2012). Consequently, photorespiration is increased and the metabolic integration of chloroplasts with mitochondria and peroxisomes via this pathway contributes to defense (Sørhagen et al., 2013). Photorespiration provides photoprotection by dissipating excess excitation energy in the absence of sufficient $\mathrm{CO}_{2}$ as an electron acceptor and reducing ROS generation as well as contributes to redox homeostasis during biotic challenge (Reumann and Corpas, 2010; Eisenhut et al., 2017). Elevated activity of the photorespiratory enzyme, serine:glyoxylate aminotransferase likely confers pathogen resistance in melon by stimulating glycolate oxidase and the intraperoxisomal production of $\mathrm{H}_{2} \mathrm{O}_{2}$, and thereby activating the immune response (Taler et al., 2004). Moreover, $\mathrm{H}_{2} \mathrm{O}_{2}$ originated in chloroplasts and peroxisomes can elicit different responses, and $\mathrm{H}_{2} \mathrm{O}_{2}$ from peroxisomes stimulates stress tolerance whereas that from chloroplasts induces early defense signaling (Sewelam et al., 2014). In Arabidopsis overexpressing glycolate oxidase in chloroplasts and the peroxisomal catalase deficient mutant cat2-2, producing increased amounts of $\mathrm{H}_{2} \mathrm{O}_{2}$ from the respective organelles, only signals generated by $\mathrm{H}_{2} \mathrm{O}_{2}$ in chloroplasts enhanced resistance to Colletotrichum higginssianum (Schmidt et al., 2020).

\section{CHLOROPLASTS AS TARGETS FOR PATHOGEN MANIPULATION}

Pathogens modify chloroplast functions for their benefit. During interactions with hemibiotrophs, this mechanism often relays on suppressing redox-linked SA pathway by activating the antagonistic JA signaling (Robert-Seilaniantz et al., 2011). Ralstonia solanacearum uses type III effector proteins called Rips (Ralstonia-injected protein) to induce JA accumulation by releasing linolenic acid with its lipase activity. Simultaneously, Rips promote bacterial pathogen growth by suppressing SA and SA-dependent signaling in infected cells (Nakano and Mukaihara, 2018). Coronatine, P. syringae phytotoxin with structural similarity to JA which promotes bacterial entry and growth, targets photosynthesis and modulates ROS balance in chloroplasts (Ishiga et al., 2009). The P. syringae toxin syringolin and the Xanthomonas campestris effector XopJ interfere with the degradation of NPR1 which redox-dependent turnover is required for SA signaling (Büttner, 2016).

Sclerotinia sclerotiorum induces stomata opening at the early stages of infection. Oxalic acid secreted by this fungus acidifies the infected tissues, stimulates NPQ by enhancing the conversion of violaxanthin to zeaxanthin and attenuates ROS generation, affecting chloroplast redox status. The dysfunction of the xanthophyll cycle limits ABA biosynthesis by decreasing the violaxanthin precursor for ABA synthesis in chloroplasts. This affects defense responses such as ROS induction and callose 
TABLE 1 | Chloroplast factors involved in plant immune response.

\begin{tabular}{|c|c|c|}
\hline Factor & Role in plant immunity & References \\
\hline $\begin{array}{l}\text { Photosynthesis- } \\
\text { derived reactive } \\
\text { oxygen species } \\
\text { (ROS) }\end{array}$ & $\begin{array}{l}\text { Contribute to pattern-triggered immunity (PTI) and effector triggered immunity (ETI) and chloroplasts are } \\
\text { the main source of ROS during hypersensitive response. Chloroplast ROS-mediated retrograde } \\
\text { signaling leads to the induction of defense gene expression. ROS generation and signaling in } \\
\text { chloroplasts follows ROS bursts in the apoplast triggered by pathogen recognition. The signaling } \\
\text { specificity of ROS depends on the chemical characteristics and the ROS-antioxidants balance in } \\
\text { chloroplast }\end{array}$ & $\begin{array}{l}\text { Zurbriggen et al., 2009; Göhre et al., } \\
\text { 2012; Nomura et al., 2012; } \\
\text { Mignolet-Spruyt et al., } 2016\end{array}$ \\
\hline Plastoquinone & $\begin{array}{l}\text { Regulates defense signaling and gene expression through } \mathrm{O}_{2}^{-} \text {and } \mathrm{H}_{2} \mathrm{O}_{2} \text { generation. Mediates ROS } \\
\text { balance and affects the activities of antioxidant enzymes. Is linked with abscisic acid (ABA)-regulated } \\
\text { defense by contributing to ABA biosynthesis }\end{array}$ & $\begin{array}{l}\text { Rock and Zeevaart, 1991; } \\
\text { Maciejewska et al., 2002; } \\
\text { Adamiec et al., 2008; Pfannschmidt } \\
\text { et al., 2009; Nosek et al., 2015; } \\
\text { Camejo et al., } 2016\end{array}$ \\
\hline Ferredoxin & $\begin{array}{l}\text { Determines the redox status of NADPH and ferredoxin-dependent thioredoxins involved in defense } \\
\text { signaling. The increased susceptibility to biotrophic and hemibiotrophic pathogens of } \\
\text { ferredoxin-knockout mutants relays on suppressing salicylic acid (SA) pathway and activating the } \\
\text { antagonistic jasmonic acid (JA) signaling; Ferredoxin localized in stromules could be involved in } \\
\text { redox-mediated transcriptome reprogramming required for activation of immune response }\end{array}$ & $\begin{array}{l}\text { Robert-Seilaniantz et al., 2011; Wang } \\
\text { et al., } 2018\end{array}$ \\
\hline $\mathrm{NADPH}$ & $\begin{array}{l}\text { Chloroplast-produced NADPH is involved in redox signaling via NTRC and used in the regeneration of } \\
\text { ascorbate and glutathione by NADPH-dependent enzymes in the ascorbate-glutathione cycle which is } \\
\text { implicated in regulating disease resistance }\end{array}$ & $\begin{array}{l}\text { Kuźniak and Skłodowska, 2005; } \\
\text { Potters et al., 2010; Hanke and Mulo, } \\
2013\end{array}$ \\
\hline $\begin{array}{l}\text { NADPH-dependent } \\
\text { thioredoxin } \\
\text { reductase (NTRC) }\end{array}$ & $\begin{array}{l}\text { The importance of the NTRC in plant immunity is shown by elevated JA signaling and enhanced } \\
\text { susceptibility of the ntrc Arabidopsis mutant to non-host pathogens }\end{array}$ & Ishiga et al., 2016 \\
\hline Thioredoxin Trx-h & $\begin{array}{l}\text { NtTRXh3 protein localized in chloroplasts is involved in tobacco resistance to viruses by contributing to } \\
\text { ROS scavenging and cellular reducing conditions. The redox status of thioredoxins affects nuclear gene } \\
\text { expression by modifying chloroplasts retrograde signaling }\end{array}$ & Rintamäki et al., 2009; Sun et al., 2010 \\
\hline Tocopherols & $\begin{array}{l}\text { Involved in the antioxidant protection of chloroplast membranes and in the transfer of stress signals } \\
\text { outside the chloroplast via plastid- endoplasmic reticulum contact sites } \\
\text { Tocopherols content and composition modulate nuclear gene expression, the profiles of defense } \\
\text { hormones and PUFA-derived defense products }\end{array}$ & $\begin{array}{l}\text { Mehrshahi et al., 2014; Müller and } \\
\text { Munné-Bosch, 2015; Allu et al., 2017; } \\
\text { Cela et al., } 2018\end{array}$ \\
\hline Apocarotenoids & $\begin{array}{l}\text { Chloroplast-generated signaling molecules produced by carotenoid cleavage link chloroplast activity } \\
\text { and nuclear gene expression. They interfere with SA signaling by regulating the localization of NPR1, a } \\
\text { redox-sensitive transcription co-activator, in the nucleus }\end{array}$ & $\begin{array}{l}\text { Bobik and Burch-Smith, 2015; } \\
\text { Brunkard et al., 2015; Hou et al., } 2016\end{array}$ \\
\hline $\begin{array}{l}\text { Polyunsaturated } \\
\text { fatty acids (PUFA) }\end{array}$ & $\begin{array}{l}\text { Biosynthetic precursors of JA which is central to modulating defense against necrotrophs, participates } \\
\text { in systemic acquired resistance and usually antagonizes SA-mediated defense } \\
\text { Independently of being the precursors of JA, PUFA are sinks for ROS in chloroplasts }\end{array}$ & $\begin{array}{l}\text { Mène-Saffrané et al., 2009; Farmer } \\
\text { and Mueller, } 2013\end{array}$ \\
\hline Oxylipins & $\begin{array}{l}\text { Reactive electrophilic species signaling molecules interfering with TGA transcription factors-mediated } \\
\text { SA pathway which also exhibit antimicrobial activity }\end{array}$ & Prost et al., 2005; Findling et al., 2018 \\
\hline $\begin{array}{l}\text { Calcium sensor } \\
\text { protein (CAS) }\end{array}$ & $\begin{array}{l}\text { Thylakoid-localized calcium-binding protein which connects chloroplasts to immune responses } \\
\text { triggered during PTI and ETI and regulates the biosynthesis of SA via the chloroplast isochorismate } \\
\text { pathway. CAS is involved in PAMP-induced defense gene expression, including SA biosynthesis genes, } \\
\text { through }{ }^{1} \mathrm{O}_{2} \text {-mediated retrograde signaling. SA generally mediates defense against } \\
\text { biotrophic/hemibiotrophic pathogens and systemic acquired resistance }\end{array}$ & $\begin{array}{l}\text { Nomura et al., 2012; Bobik and } \\
\text { Burch-Smith, } 2015\end{array}$ \\
\hline
\end{tabular}

deposition which increases plant susceptibility to Sclerotinia (Zhou et al., 2015; Zeng et al., 2020).

$P$. syringae effector HopN1 targets the oxygen-evolving complex of PSII, suppresses cell death, attenuates ROS production, callose deposition, and the formation of defense signals in Arabidopsis chloroplasts (Rodríguez-Herva et al., 2012). HopI1, the P. syringae pv maculicola effector localizes to chloroplasts, suppresses SA accumulation, and affects thylakoid stacking (Jelenska et al., 2007). It also recruits cytosolic Hsp70 to chloroplasts suppressing the function of cytosolic Hsp70 in basal defense (Jelenska et al., 2010). Chloroplast proteins identified as targets of virus effectors are components of the PETC (e.g., ferredoxin, Rieske Fe-S), the PSII oxygen-evolving complex and Rubisco, which supports the chloroplast role in plant defense (Bobik and Burch-Smith, 2015).

\section{CONCLUSION}

The organelle-organelle contacts and inter-compartment communication initiated at the plasma membrane on pathogen recognition are essential for defense. Chloroplasts have emerged as regulatory hubs connecting the primary metabolism and plant defense. They participate in PTI and ETI through ROS/redox systems, retrograde signaling, and phytohormones (Table 1). Chloroplasts are the source and the target of redox regulations which are integrated to the interorganellar signaling network and contribute to the outcome of the plant immune response. Therefore, our integrated understanding of the redoxmediated functions of chloroplasts in photosynthesis and plant immunity will be highly relevant in developing new crops with broad-spectrum resistance to pathogens. 


\section{AUTHOR CONTRIBUTIONS}

EK and TK took responsibility for the integrity of the work as a whole. Both authors contributed to the article and approved the submitted version.

\section{REFERENCES}

Adamiec, M., Drath, M., and Jackowski, G. (2008). Redox state of plastoquionone pool regulates expression of Arabidopsis thaliana genes in response to elevated irradiance .Acta Biochim. Pol. 55, 161-173. doi: 10.18388/abp.2008_ 3176

Allu, A. D., Simancas, B., Balazadeh, S., and Munné-Bosch, S. (2017). Defenserelated transcriptional reprogramming in vitamin E-deficient Arabidopsis mutants exposed to contrasting phosphate availability. Front. Plant Sci. 8:1396. doi: $10.3389 /$ fpls.2017.01396

Baier, M., and Dietz, K. J. (2005). Chloroplasts as source and target of cellular redox regulation: a discussion on chloroplast redox signals in the context of plant physiology. J. Exp. Bot. 56, 1449-1462. doi: 10.1093/jxb/eri161

Balint-Kurti, P. (2019). The plant hypersensitive response: concepts, control and consequences. Mol. Plant Pathol. 20, 1163-1178. doi: 10.1111/mpp.12821

Bobik, K., and Burch-Smith, T. M. (2015). Chloroplast signaling within, between and beyond cells. Front. Plant Sci. 6:781. doi: 10.3389/fpls.2015.00781

Brunkard, J. O., Runkel, A. M., and Zambryski, P. C. (2015). Chloroplasts extend stromules independently and in response to internal redox signals. Proc. Natl. Acad. Sci. U.S.A. 112, 10044-10049. doi: 10.1073/pnas.1511570112

Büttner, D. (2016). Behind the lines-actions of bacterial type III effector proteins in plant cells. FEMS Microbiol. Rev. 40, 894-937. doi: 10.1093/femsre/fuw026

Camejo, D., Guzmán-Cedeño, Á, and Moreno, A. (2016). Reactive oxygen species, essential molecules, during plant-pathogen interactions. Plant Physiol. Biochem. 103, 10-23. doi: 10.1016/j.plaphy.2016.02.035

Caplan, J. L., Kumar, A. S., Park, E., Padmanabhan, M. S., Hoban, K., Modla, S., et al. (2015). Chloroplast stromules function during innate immunity. Dev. Cell 34, 45-57. doi: 10.1016/j.devcel.2015.05.011

Cela, J., Tweed, J. K. S., Sivakumaran, A., Lee, M. R. F., Mur, L. A. J., and MunnéBosch, S. (2018). An altered tocopherol composition in chloroplasts reduces plant resistance to Botrytis cinerea. Plant Physiol. Biochem. 127, 200-210. doi: 10.1016/j.plaphy.2018.03.033

Cook, D. E., Mesarich, C. H., and Thomma, B. P. H. J. (2015). Understanding plant immunity as a surveillance system to detect invasion. Annu. Rev. Phytopathol. 53, 541-563. doi: 10.1146/annurev-phyto-080614-120114

Corpas, F. J., Alché, J. D., and Barroso, J. B. (2013). Current overview of S-nitrosoglutathione (GSNO) in higher plants. Front. Plant Sci. 4:126. doi: 10.3389/fpls.2013.00126

Das, K., and Roychoudhury, A. (2014). Reactive oxygen species (ROS) and response of antioxidants as ROS-scavengers during environmental stress in plants. Front. Environ. Sci. 2:53. doi: 10.3389/fenvs.2014.00053

de Torres Zabala, M., Littlejohn, G., Jayaraman, S., Studholme, D., Bailey, T., Lawson, T., et al. (2015). Chloroplasts play a central role in plant defence and are targeted by pathogen effectors. Nat. Plants 1:15074. doi: 10.1038/NPLANTS. 2015.74

Dietz, K.-J., Wesemann, C., Wegener, M., and Seidel, T. (2019). Toward an integrated understanding of retrograde control of photosynthesis. Antioxid. Redox Signal. 30, 1186-1205. doi: 10.1089/ars.2018.7519

Ding, P., and Ding, Y. (2020). Stories of salicylic acid: a plant defense hormone. Trends Plant Sci. 1, 1-17. doi: 10.1016/j.tplants.2020.01.004

Ding, X., Jimenez-Gongora, T., Krenz, B., and Lozano-Duran, R. (2019). Chloroplast clustering around the nucleus is a general response to pathogen perception in Nicotiana benthamiana. Mol. Plant Pathol. 20, 1298-1306. doi: 10.1111/mpp. 12840

Eisenhut, M., Bräutigam, A., Timm, S., Florian, A., Tohge, T., Fernie, A. R., et al. (2017). Photorespirationis crucial for dynamic response of photosynthetic metabolism and stomatal movement to altered CO2 availability. Mol. Plant 10, 47-61. doi: 10.1016/j.molp.2016.09.011

Exposito-Rodriguez, M., Laissue, P. P., Yvon-Durocher, G., Smirnoff, N., and Mullineaux, P. M. (2017). Photosynthesis-dependent H2O2 transfer from

\section{ACKNOWLEDGMENTS}

This work was supported by Grant No. 2013/11/N/ NZ9/00116 from the National Science Centre (NCN, Poland).

chloroplasts to nuclei provides a high-light signalling mechanism. Nat. Commun. 8:49. doi: 10.1038/s41467-017-00074-w

Farmer, E. E., and Mueller, M. J. (2013). ROS-mediated lipid peroxidation and RESactivated signaling. Annu. Rev. Plant Biol. 64, 429-450. doi: 10.1146/annurevarplant-050312-120132

Fey, V., Wagner, R., Bräutigam, K., Wirtz, M., Hell, R., Dietzmann, A., et al. (2005). Retrograde plastid redox signals in the expression of nuclear genes for chloroplast proteins of Arabidopsis thaliana. J. Biol. Chem. 280, 5318-5328. doi: 10.1074/jbc.M406358200

Findling, S., Stotz, H. U., Zoeller, M., Krischke, M., Zander, M., Gatz, C., et al. (2018). TGA2 signaling in response to reactive electrophile species is not dependent on cysteine modification of TGA2. PLoS One 13:e0195398. doi: 10.1371/journal.pone.0195398

Fobert, P. R., and Després, C. (2005). Redox control of systemic acquired resistance. Curr. Opin. Plant Biol. 8, 378-382. doi: 10.1016/j.pbi.2005.05.003

Foyer, C. H. (2018). Reactive oxygen species, oxidative signaling and the regulation of photosynthesis. Environ. Exp. Bot. 154, 134-142. doi: 10.1016/j.envexpbot. 2018.05.003

Frederickson Matika, D. E., and Loake, G. J. (2014). Redox regulation in plant immune function. Antioxid. Redox Signal. 21, 1373-1388. doi: 10.1089/ars.2013. 5679

Gabara, B., Kuźniak, E., Skłodowska, M., Surówka, E., and Miszalski, Z. (2012). Ultrastructural and metabolic modifications at the plant-pathogen interface in Mesembryanthemum crystallinum leaves infected by Botrytis cinerea. Environ. Exp. Bot. 77, 33-43. doi: 10.1016/j.envexpbot.2011.10.010

Göhre, V., Jones, A. M. E., Sklenáŕ, J., Robatzek, S., and Weber, A. P. M. (2012). Molecular crosstalk between PAMP-triggered immunity and photosynthesis Mol. Plant Microbe Interact. 25, 1083-1092. doi: 10.1094/MPMI-11-11-0301

Govrin, E. M., and Levine, A. (2000). The hypersensitive response facilitates plant infection by the necrotrophic pathogen Botrytis cinerea. Curr. Biol. 10, 751-757. doi: 10.1016/S0960-9822(00)00560-1

Grimmer, M. K., John Foulkes, M., and Paveley, N. D. (2012). Foliar pathogenesis and plant water relations: a review. J. Exp. Bot. 63, 4321-4331. doi: 10.1093/jxb/ ers143

Hanke, G., and Mulo, P. (2013). Plant type ferredoxins and ferredoxin-dependent metabolism. Plant Cell Environ. 36, 1071-1084. doi: 10.1111/pce.12046

Herrera-Vásquez, A., Salinas, P., and Holuigue, L. (2015). Salicylic acid and reactive oxygen species interplay in the transcriptional control of defense genes expression. Front. Plant Sci. 6:171. doi: 10.3389/fpls.2015.00171

Hou, X., Rivers, J., León, P., McQuinn, R. P., and Pogson, B. J. (2016). Synthesis and function of apocarotenoid signals in plants. Trends Plant Sci. 21, 792-803. doi: 10.1016/j.tplants.2016.06.001

Ishiga, Y., Ishiga, T., Ikeda, Y., Matsuura, T., and Mysore, K. S. (2016). NADPHdependent thioredoxin reductase $\mathrm{C}$ plays a role in nonhost disease resistance against Pseudomonas syringae pathogens by regulating chloroplast-generated reactive oxygen species. PeerJ 4:e1938. doi: 10.7717/peerj.1938

Ishiga, Y., Uppalapati, S. R., Ishiga, T., Elavarthi, S., Martin, B., and Bender, C. L. (2009). The phytotoxin coronatine induces light-dependent reactive oxygen species in tomato seedlings. New Phytol. 181, 147-160. doi: 10.1111/j.14698137.2008.02639.x

Jelenska, J., Van Hal, J. A., and Greenberg, J. T. (2010). Pseudomonas syringae hijacks plant stress chaperone machinery for virulence. Proc. Natl. Acad. Sci. U.S.A. 107, 13177-13182. doi: 10.1073/pnas.0910943107

Jelenska, J., Yao, N., Vinatzer, B. A., Wright, C. M., Brodsky, J. L., and Greenberg, J. T. (2007). A J domain virulence effector of Pseudomonas syringae remodels host chloroplasts and suppresses defenses. Curr. Biol. 17, 499-508. doi: 10.1016/ j.cub.2007.02.028

Karasov, T. L., Chae, E., Herman, J. J., and Bergelson, J. (2017). Mechanisms to mitigate the trade-off between growth and defense. Plant Cell 29, 666-680. doi: $10.1105 /$ tpc. 16.00931 
Karpiński, S., Szechyńska-Hebda, M., Wituszyńska, W., and Burdiak, P. (2013). Light acclimation, retrograde signalling, cell death and immune defences in plants. Plant Cell Environ. 36, 736-744. doi: 10.1111/pce.12018

Kuźniak, E., Kornas, A., Gabara, B., Ullrich, C., Skłodowska, M., and Miszalski, Z. (2010). Interaction of Botrytis cinerea with the intermediate C3-CAM plant Mesembryanthemum crystallinum. Environ. Exp. Bot. 69, 137-147. doi: 10.1016/ j.envexpbot.2010.03.010

Kuźniak, E., and Skłodowska, M. (2005). Compartment-specific role of the ascorbate-glutathione cycle in the response of tomato leaf cells to Botrytis cinerea infection. J. Exp. Bot. 56, 921-933. doi: 10.1093/jxb/eri086

Larkin, R. M. (2016). Tetrapyrrole signaling in plants. Front. Plant Sci. 7:1586. doi: 10.3389/fpls.2016.01586

Lindermayr, C., Sell, S., Müller, B., Leister, D., and Durner, J. (2010). Redox regulation of the NPR1-TGA1 system of Arabidopsis thaliana by nitric oxide. Plant Cell 22, 2894-2907. doi: 10.1105/tpc.109.066464

Liu, M., and Lu, S. (2016). Plastoquinone and ubiquinone in plants: biosynthesis, physiological function and metabolic engineering. Front. Plant Sci. 7:1898. doi: 10.3389/fpls.2016.01898

Liu, Y., Ren, D., Pike, S., Pallardy, S., Gassmann, W., and Zhang, S. (2007). Chloroplast-generated reactive oxygen species are involved in hypersensitive response-like cell death mediated by a mitogen-activated protein kinase cascade. Plant J. 51, 941-954. doi: 10.1111/j.1365-313X.2007.03191.x

$\mathrm{Lu}, \mathrm{Y}$., and Yao, J. (2018). Chloroplasts at the crossroad of photosynthesis, pathogen infection and plant defense. Int. J. Mol. Sci. 19, 1-37. doi: 10.3390/ijms 19123900

Maciejewska, U., Polkowska-Kowalczyk, L., Swiezewska, E., and Szkopinska, A. (2002). Plastoquinone: possible involvement in plant disease resistance. Acta Biochim. Pol. 49, 775-780. doi: 10.18388/abp.2002_3785

Mauch, F., Mauch-Mani, B., Gaille, C., Kull, B., Haas, D., and Reimmann, C. (2001). Manipulation of salicylate content in Arabidopsis thaliana by the expression of an engineered bacterial salicylate. Plant J. 25, 67-77. doi: 10.1046/j.1365-313X. 2001.00940.x

Mehrshahi, P., Johnny, C., and DellaPenna, D. (2014). Redefining the metabolic continuity of chloroplasts and ER. Trends Plant Sci. 19, 501-507. doi: 10.1016/ j.tplants.2014.02.013

Melotto, M., Underwood, W., and He, S. Y. (2008). Role of stomata in plant innate immunity and foliar bacterial diseases. Annu. Rev. Phytopathol. 46, 101-122. doi: 10.1146/annurev.phyto.121107.104959

Mène-Saffrané, L., Dubugnon, L., Chételat, A., Stolz, S., Gouhier-Darimont, C., and Farmer, E. E. (2009). Nonenzymatic oxidation of trienoic fatty acids contributes to reactive oxygen species management in Arabidopsis. J. Biol. Chem. 284, 1702-1708. doi: 10.1074/jbc.M807114200

Mignolet-Spruyt, L., Xu, E., Idänheimo, N., Hoeberichts, F. A., Mühlenbock, P., Brosche, M., et al. (2016). Spreading the news: subcellular and organellar reactive oxygen species production and signalling. J. Exp. Bot. 67, 3831-3844. doi: 10.1093/jxb/erw080

Mühlenbock, P., Szechyńska-Hebda, M., Płaszczyca, M., Baudo, M., Mateo, A., Mullineaux, P. M., et al. (2008). Chloroplast signaling and lesion simulating disease1 regulate crosstalk between light acclimation and immunity in Arabidopsis. Plant Cell 20, 2339-2356. doi: 10.1105/tpc.108.059618

Müller, M., and Munné-Bosch, S. (2015). Ethylene response factors: a key regulatory hub in hormone and stress signaling. Plant Physiol. 169, 32-41. doi: 10.1104/pp.15.00677

Nakano, M., and Mukaihara, T. (2018). Ralstonia solanacearum type III effector RipAL targets chloroplasts and induces jasmonic acid production to suppress salicylic acid-mediated defense responses in plants. Plant Cell Physiol. 59, 2576-2589. doi: 10.1093/pcp/pcy177

Nelson, R. (2020). International plant pathology: past and future contributions to global food security. Phytopathology 110, 245-253. doi: 10.1094/PHYTO-0819-0300-IA

Noctor, G., Queval, G., and Gakière, B. (2006). NAD(P) synthesis and pyridine nucleotide cycling in plants and their potential importance in stress conditions. J. Exp. Bot. 57, 1603-1620. doi: 10.1093/jxb/erj202

Nomura, H., Komori, T., Uemura, S., Kanda, Y., Shimotani, K., Nakai, K., et al. (2012). Chloroplast-mediated activation of plant immune signalling in Arabidopsis. Nat. Commun. 3:926. doi: 10.1038/ncomms1926

Nosek, M., Kornaś, A., Kuźniak, E., and Miszalski, Z. (2015). Plastoquinone redox state modifies plant response to pathogen. Plant Physiol. Biochem. 96, 163-170. doi: 10.1016/j.plaphy.2015.07.028
Park, E., Nedo, A., Caplan, J. L., and Dinesh-Kumar, S. P. (2018). Plant-microbe interactions: organelles and the cytoskeleton in action. New Phytol. 217, 10121028. doi: 10.1111/nph.14959

Pfannschmidt, T., Bräutigam, K., Wagner, R., Dietzel, L., Schröter, Y., Steiner, S., et al. (2009). Potential regulation of gene expression in photosynthetic cells by redox and energy state: approaches towards better understanding. Ann. Bot. 103, 599-607. doi: 10.1093/aob/mcn081

Pieterse, C. M. J., Leon-Reyes, A., Van Der Ent, S., and Van Wees, S. C. M. (2009). Networking by small-molecule hormones in plant immunity. Nat. Chem. Biol. 5, 308-316. doi: 10.1038/nchembio.164

Potters, G., Horemans, N., and Jansen, M. A. K. (2010). The cellular redox state in plant stress biology - a charging concept. Plant Physiol. Biochem. 48, 292-300. doi: 10.1016/j.plaphy.2009.12.007

Prost, I., Dhondt, S., Rothe, G., Vicente, J., Rodriguez, M. J., Kift, N., et al. (2005). Evaluation of the antimicrobial activities of plant oxylipins supports their involvement in defense against pathogens. Plant Physiol. 139, 1902-1913. doi: 10.1104/pp.105.066274

Reumann, S., and Corpas, F. J. (2010). “The peroxisomal ascorbate- glutathione pathway: molecular identification and insights into its essential role under environmental stress conditions," in Ascorbate-Glutathione Pathway and Stress Tolerance in Plants, eds N. A. Anjum, M.-T. Chan, and S. Umar (Dordrecht: Springer), 387-404. doi: 10.1007/978-90-481-9404-9_14

Rintamäki, E., Lepistö, A., and Kangasjärvi, S. (2009). Implication of chlorophyll biosynthesis on chloroplast-to-nucleus retrograde signaling. Plant Signal. Behav. 4, 545-547. doi: 10.4161/psb.4.6.8711

Robert-Seilaniantz, A., Grant, M., and Jones, J. D. G. (2011). Hormone crosstalk in plant disease and defense: more than just jasmonate-salicylate antagonism. Annu. Rev. Phytopathol. 49, 317-343. doi: 10.1146/annurev-phyto-073009114447

Rock, C. D., and Zeevaart, J. A. D. (1991). The aba mutant of Arabidopsis thaliana is impaired in epoxy-carotenoid biosynthesis. Proc. Natl. Acad. Sci. U.S.A. 88, 7496-7499. doi: 10.1073/pnas.88.17.7496

Roden, L. C., and Ingle, R. A. (2009). Lights, rhythms, infection: the role of light and the circadian clock in determining the outcome of plant-pathogen interactions. Plant Cell 21, 2546-2552. doi: 10.1105/tpc.109.069922

Rodríguez-Herva, J. J., González-Melendi, P., Cuartas-Lanza, R., Antúnez-Lamas, M., Río-Alvarez, I., Li, Z., et al. (2012). A bacterial cysteine protease effector protein interferes with photosynthesis to suppress plant innate immune responses. Cell. Microbiol. 14, 669-681. doi: 10.1111/j.1462-5822.2012. 01749.x

Rossi, F. R., Krapp, A. R., Bisaro, F., Maiale, S. J., Pieckenstain, F. L., and Carrillo, N. (2017). Reactive oxygen species generated in chloroplasts contribute to tobacco leaf infection by the necrotrophic fungus Botrytis cinerea. Plant J. 92, 761-773. doi: $10.1111 /$ tpj. 13718

Saxena, I., Srikanth, S., and Chen, Z. (2016). Cross talk between H2O2 and interacting signal molecules under plant stress response. Front. Plant Sci. 7:570. doi: 10.3389/fpls.2016.00570

Schmidt, A., Mächtel, R., Ammon, A., Engelsdorf, T., Schmitz, J., Maurino, V. G., et al. (2020). Reactive oxygen species dosage in Arabidopsis chloroplasts can improve resistance towards Colletotrichum higginsianum by the induction of WRKY33. New Phytol. 226, 189-204. doi: 10.1111/nph. 16332

Sewelam, N., Jaspert, N., Van Der Kelen, K., Tognetti, V. B., Schmitz, J., Frerigmann, H., et al. (2014). Spatial H2O2 signaling specificity: H2O2 from chloroplasts and peroxisomes modulates the plant transcriptome differentially. Mol. Plant 7, 1191-1210. doi: 10.1093/mp/ssu070

Seyfferth, C., and Tsuda, K. (2014). Salicylic acid signal transduction: the initiation of biosynthesis, perception and transcriptional reprogramming. Front. Plant Sci. 5:697. doi: 10.3389/fpls.2014.00697

Shapiguzov, A., Vainonen, J. P., Wrzaczek, M., and Kangasjärvi, J. (2012). ROStalk - how the apoplast, the chloroplast, and the nucleus get the message through. Front. Plant Sci. 3:292. doi: 10.3389/fpls.2012.00292

Sørhagen, K., Laxa, M., Peterhänsel, C., and Reumann, S. (2013). The emerging role of photorespiration and non-photorespiratory peroxisomal metabolism in pathogen defence. Plant Biol. 15, 723-736. doi: 10.1111/j.1438-8677.2012. 00723.x

Sowden, R. G., Watson, S. J., and Jarvis, P. (2018). The role of chloroplasts in plant pathology. Essays Biochem. 62, 21-39. doi: 10.1042/EBC20170020 
Sun, L., Ren, H., Liu, R., Li, B., Wu, T., Sun, F., et al. (2010). An h-Type thioredoxin functions in tobacco defense responses to two species of viruses and an abiotic oxidative stress. Mol. Plant-Microbe Interact. 23, 1470-1485. doi: 10.1094/MPMI-01-10-0029

Taler, D., Galperin, M., Benjamin, I., Cohen, Y., and Kenigsbuch, D. (2004). Plant eR genes that encode photorespiratory enzymes confer resistance against disease. Plant Cell 16, 172-184. doi: 10.1105/tpc.016352

Virdi, K. S., Laurie, J. D., Xu, Y. Z., Yu, J., Shao, M. R., Sanchez, R., et al. (2015). Arabidopsis MSH1 mutation alters the epigenome and produces heritable changes in plant growth. Nat. Commun. 6:6386. doi: 10.1038/ncomms7386

Wang, M., Rui, L., Yan, H., Shi, H., Zhao, W., Lin, J. E., et al. (2018). The major leaf ferredoxin Fd2 regulates plant innate immunity in Arabidopsis. Mol. Plant Pathol. 19, 1377-1390. doi: 10.1111/mpp.12621

Yao, N., and Greenberg, J. T. (2006). Arabidopsis accelerated cell death2 modulates programmed cell death. Philos. Trans. R. Soc. B 18, 397-411. doi: 10.1105/tpc. 105.036251

Zechmann, B. (2019). Ultrastructure of plastids serves as reliable abiotic and biotic stress marker. PLoS One 14:e0214811. doi: 10.1371/journal.pone. 0214811

Zeng, L., Yang, X., and Zhou, J. (2020). The xanthophyll cycle as an early pathogenic target to deregulate guard cells during Sclerotinia sclerotiorum infection. Plant Signal. Behav. 15, 1. doi: 10.1080/15592324.2019. 1691704
Zhou, J., Zeng, L., Liu, J., and Xing, D. (2015). Manipulation of the xanthophyll cycle increases plant susceptibility to Sclerotinia sclerotiorum. PLoS Pathog. 11:e1004878. doi: 10.1371/journal.ppat.1004878

Zoeller, M., Stingl, N., Krischke, M., Fekete, A., Waller, F., Berger, S., et al. (2012). Lipid profiling of the Arabidopsis hypersensitive response reveals specific lipid peroxidation and fragmentation processes: biogenesis of pimelic and azelaic acid. Plant Physiol. 160, 365-378. doi: 10.1104/pp.112.202846

Zurbriggen, M. D., Carrillo, N., Tognetti, V. B., Melzer, M., Peisker, M., Hause, B., et al. (2009). Chloroplast-generated reactive oxygen species play a major role in localized cell death during the non-host interaction between tobacco and Xanthomonas campestris pv. vesicatoria. Plant J. 60, 962-973. doi: 10.1111/j. 1365-313X.2009.04010.x

Conflict of Interest: The authors declare that the research was conducted in the absence of any commercial or financial relationships that could be construed as a potential conflict of interest.

Copyright (C) 2020 Kuźniak and Kopczewski. This is an open-access article distributed under the terms of the Creative Commons Attribution License (CC BY). The use, distribution or reproduction in other forums is permitted, provided the original author(s) and the copyright owner(s) are credited and that the original publication in this journal is cited, in accordance with accepted academic practice. No use, distribution or reproduction is permitted which does not comply with these terms. 